\title{
FULL SCALE FIELD TESTING FOR PERFORMANCE EVALUATION AND RETROFITTING OF OPEN WEB GIRDER TYPE ROAD CUM RAILWAY BRIDGE
}

\author{
V. Srinivas ${ }^{1}$, Saptarshi Sasmal ${ }^{2}$, Nawal Kishor Banjara ${ }^{3}$, A. Kanchana Devi ${ }^{4}$, B.S. Sindu ${ }^{5}$, \\ K. Ramanjaneyulu ${ }^{6}$ \\ ${ }^{1,2,3,4,5}$ Scientist, CSIR-Structural Engineering Research Centre, (Council of Scientific \& Industrial Research), CSIR \\ Campus, TTTI(Post), Taramani, ,Chennai-600 113, India \\ ${ }^{6}$ Chief Scientist, CSIR-Structural Engineering Research Centre, (Council of Scientific \& Industrial Research), CSIR \\ Campus, TTTI(Post), Taramani, ,Chennai-600 113, India \\ Ph : +91 44 22549237/210/198, srinivas@serc.res.in; voggu.srinivas@gmail.com
}

\begin{abstract}
Synopsis
Field testing and evaluating the structural performance of bridges is becoming essential as most of the bridges that are serving are becoming old and deteriorating because of environmental effects, increase in vehicular loading, poor maintenance etc. The present paper discusses the full scale field testing carried out on a rail cum road bridge of open web girder type of truss bridge configuration. As the bridge experiences damages to some of the members, it became necessary to investigate and assess the performance of the bridge through field tests and analytical studies. Instrumentation and field testing of the bridge has been carried out to measure the structural and vibration responses of damaged and undamaged portals of the bridge span under moving vehicular and train loading. Numerical modeling at both global and local level is carried out to simulate the responses obtained from the field testing. It is found that, the cross girders of the portal at intermediate expansion joint locations are subjected to excessive torsion due to improper seating of the stringer beams at the edge of the cross girder flange. By assessing the requirement and envisaging the practical suitability, a suitable rehabilitation scheme has been proposed.
\end{abstract}

Keywords Open web girder rail cum road bridge; full-scale field testing; vibration monitoring; damage assessment; retrofitting;

\section{INTRODUCTION}

Bridges are the vital link for the highway and railway networks. There has been much progress in bridge design in recent years with increasing use of advanced analytical design methods, use of new materials and new bridge concepts. There have also been many advances in instrumentation which can monitor and analyse data to provide accurate information on the actual performance of bridges in-service. Bridge once constructed has to perform efficiently throughout its life period in a cost-effective manner. During its life cycle the structure will undergo extensive deterioration and damage by exposure to severe atmosphere, unexpected overloading due to natural hazards like earthquake and disastrous cyclones etc. For damaged bridges, selection of different rectification measures to improve the safe performance, providing control posts for load regulation, decision for replacement of the structure rather than rehabilitation etc. are decided based on existing condition of the bridge. The assessment of residual strength involves use of expensive instrumentation and advanced mathematical computations. It is necessary to formulate a systematic method to evaluate the performance and future needs of existing bridges that would help the decision makers involved in deciding the most deserving bridges for improvement during a given period. Advances in instrumentation helps to acquire data pertaining to the performance of in-service bridges ${ }^{1}$. The instrumentation procedures, if properly applied, can provide improved understanding of the bridge behaviour and performance that will enable bridge engineers to promptly monitor, maintain and undertake the repair/retrofitting of bridges ${ }^{2}$.

Performance monitoring of bridges can provide many benefits to bridge engineers, constructors and operators which include verification of the designs, monitoring construction activities, usage and performance monitoring, identification of the distresses, modifications if any required in the designs, condition assessment, planning of maintenance strategies etc. Since 1996, researchers from the Association of American Railroads (AAR) ${ }^{3}$ subsidiary Transportation Technology Center, Inc. (TTCI) ${ }^{4}$ and the University of Illinois at Urbana-Champaign ${ }^{5}$ have undertaken a series of full scale field investigations on the bridge to determine the magnitude of forces due to locomotives under tractive effort and dynamic breaking into 
the superstructure and substructure of a railway bridge. A number of researchers attempted to evaluate the performance of steel bridges subjected to railway loading by carrying out field investigations and response monitoring. Maragakis et al. ${ }^{6}$ conducted full-scale load tests up to failure on a railway two-span steel-deck girder bridge to evaluate the ultimate load capacity and to determine the role of rails, ties and ballast on the global performance of the bridge under seismic loading. Assessment of an integral type railway bridge was carried out by Karoumi et al. ${ }^{7}$ under actual traffic loads by implementing a Bridge Weigh-inMotion system. Also, numerical simulation was proposed to study the effect of traffic load on the performance of the bridge. A special test train was used by Caglayan et al. ${ }^{8}$ to evaluate the dynamic parameters and the safety index of existing steel railway bridges which were further used to refine the finite element models. Strain monitoring of an existing steel railway bridge was reported by Costa and Figueiras ${ }^{9}$ to evaluate the efficacy of electric resistance and fiber-optic strain sensors for obtaining the relevant responses towards service condition and fatigue assessment of bridges. Esmaeili and Fatollahzadeh ${ }^{10}$ carried out studies to evaluate the lateral-induced pressure on the railway bridge abutments due to the railway live load. Numerical simulation studies of a short span railway bridge were carried out by Rocha et al. ${ }^{11}$ to determine the variability of main structural parameters, which will have an influence on the dynamic response of the bridges. Srinivas et al. ${ }^{12,13,14}$ carried out extensive full scale field investigations on steel, concrete, masonry railway bridges towards evaluating their performance under increased axle loads and to assess the longitudinal forced exerted on the bridge.

In the present study, full scale field testing carried out on an Open Web Girder (OWG) type of rail cum road steel truss bridge towards obtaining the responses of a typical damaged and undamaged portals of the bridge under both vehicular loads on the roadway and passage of trains is discussed. Numerical modelling at both global and local level is carried out to simulate the responses obtained from the field testing. It is found that, the cross girders of the portal at intermediate expansion joint locations are subjected to excessive torsion due to improper seating of the stringer beams at the edge of the cross girder flange. By assessing the requirement and envisaging the practical suitability, a suitable rehabilitation scheme has been proposed.

\section{DESCRIPTION OF THE BRIDGE}

The bridge under the present investigation is a rail cum road bridge over river Ganges on the East Central Railway (ECR) zone of Indian Railways. This bridge is the life line for North-Eastern states of India. The bridge was commissioned in the year 1959. This is an Open Web Girder (OWG) type of steel truss bridge consisting of two shore spans of $31.93 \mathrm{~m}$ and 14 main spans of $121.047 \mathrm{~m}$. The lower deck of the bridge is through type which cater to single line rail track and upper deck cater to the national highways having carriageway of $7.5 \mathrm{~m}$. The loading standard adopted for the design for railway track is Broad Gauge Main Line Loading (BGML) as per Indian Railway Standard ${ }^{15}$ Bridge Rules, while road deck is designed for single lane Class - AA or double lane Class-A loading standard as per IRC- $6^{16}$. The general view of the bridge is shown in Fig.1.

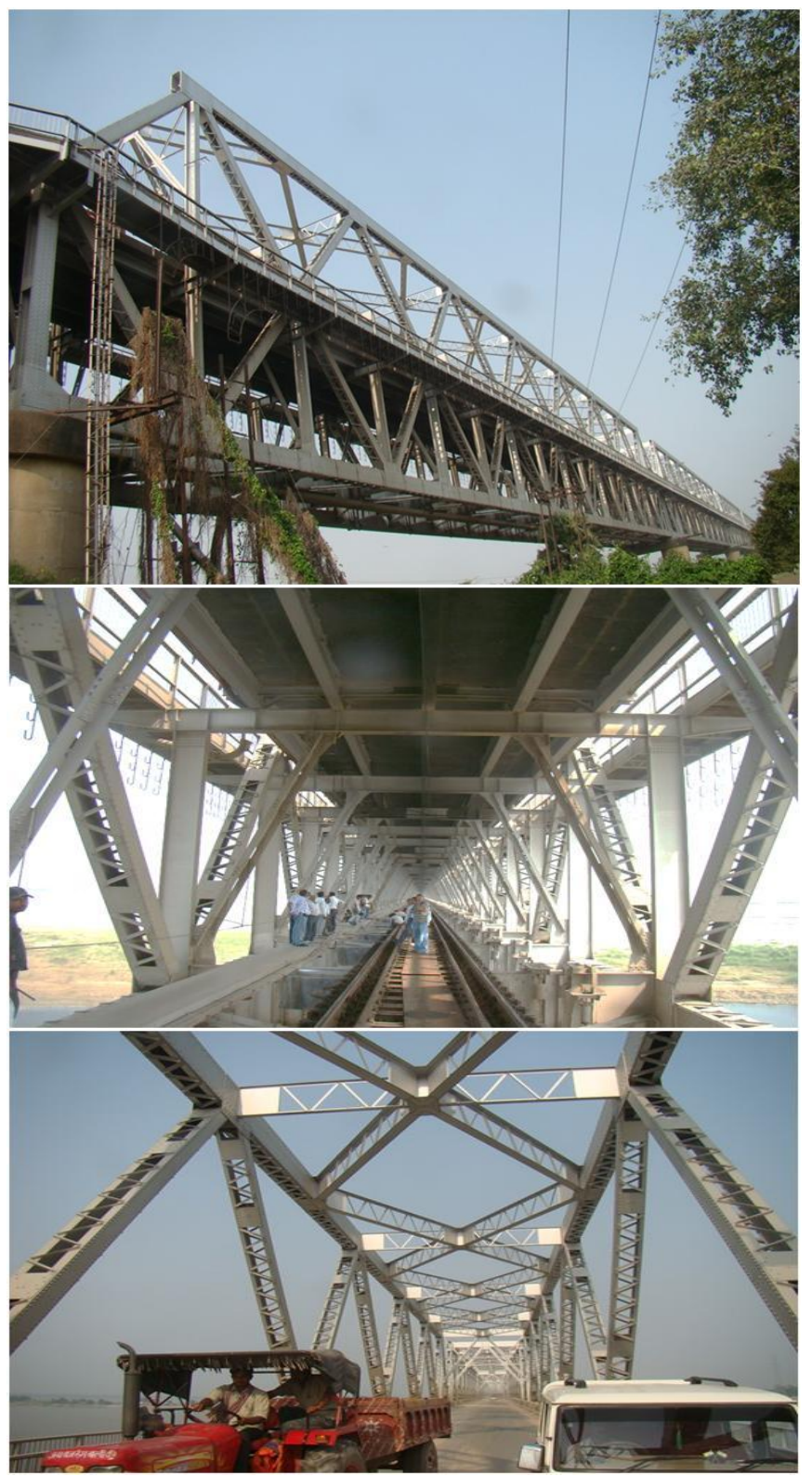

Fig.1 General view of the Open Web Girder Road cum Rail Bridge

\section{PRELIMINARY INVESTIGATION}

In order to carry out the instrumentation and measurement of responses from the bridge to assess the behaviour of the members, preliminary inspection of the bridge has been carried out. During the investigations, it is observed that the road deck slab in each span has been cast in three parts with two intermediate expansion joints and thus there are 28 nos. of intermediate expansion joints in the road deck. These expansion joints are of compression seal type made up of mild steel angles with gap filled up with rubber material. 
Cracking was observed in gusset plates connecting the road cross-girders and bracings at the location of intermediate expansion joint. Cracks are also observed in bottom flange of the road cross girders which are just below the intermediate expansion joints of the spans. The formation of cracks on cross girders, gussets etc, are identified and the bridge is observed to be experiencing vibration. Deterioration of seats in the intermediate expansion joints is noticed. Some typical damages observed on the structural members of the bridge is shown in Fig.2. The probable reasons for the failure is observed to be due to the passage of heavily loaded trucks which are more than the designed load and may be due to impact by the vehicles due to uneven road surfaces, expansion joints etc.

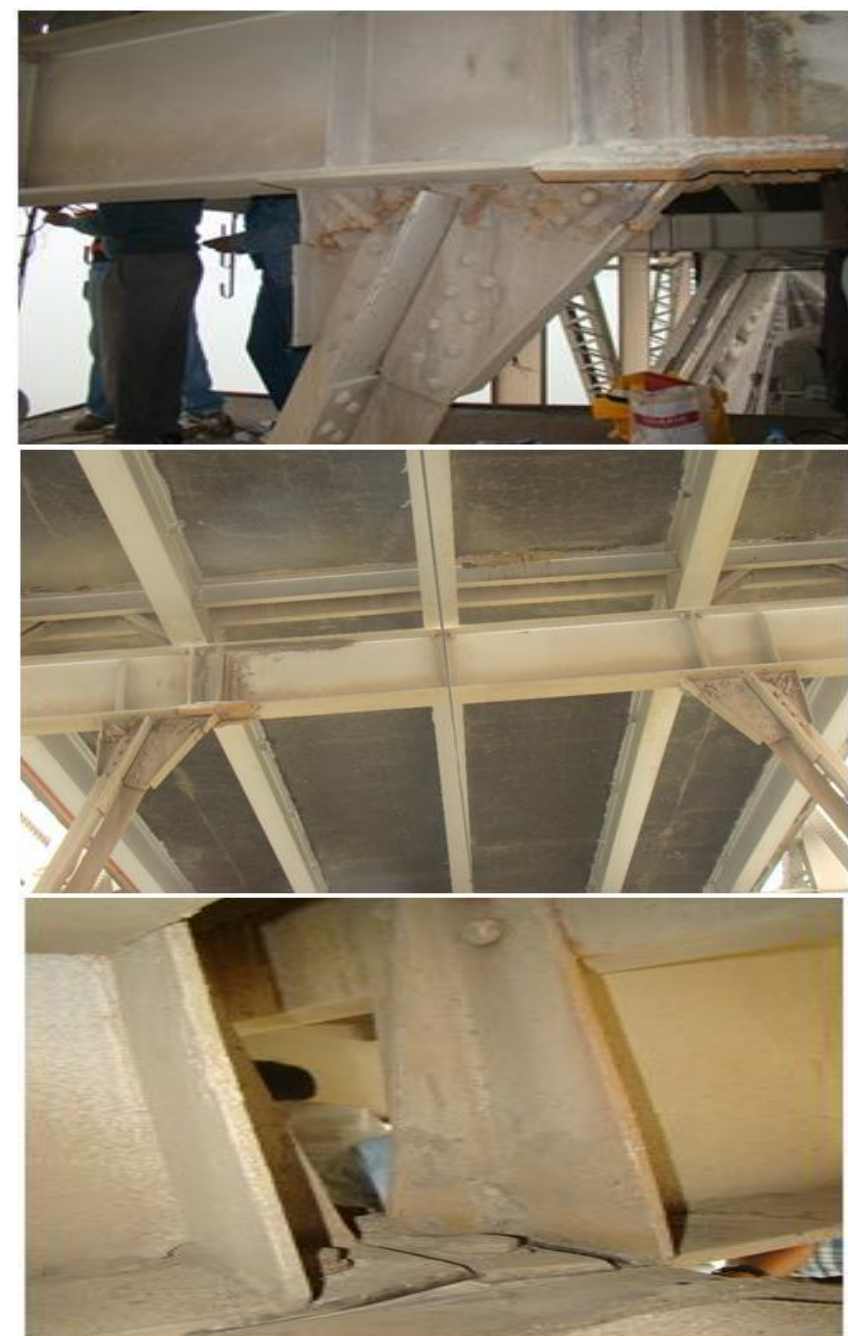

Fig.2 Damages observed in the structural members of the bridge

\section{INSTRUMENTATION AND RESPONSE MEASUREMENTS OF THE BRIDGE}

Inorder to identify the critical locations for the sensors by identifying the high stress concentraton zones, numerical simulation is carried out for the bridge using finite element software. Based on the global model of the entire bridge span and local modelling of the affected portal frame, critical locations are identified on the cross-girders, vertical members and bracings of the damaged and undamaged portals. Detailed instrumentation strategy is formulated based on the preliminary investigations at site and on numerical models to measure the responses at bridge site. Instrumentation has been carried out on two portal frames, one is damaged and the other is adjacent similar portal in undamaged condition. The adopted instrumentation scheme consists of strain gages at the identified critical locations on the cross girder, vertical members, bracings and on the gussets of the portal to measure the strain responses under the vehicular load passing on the bridge.

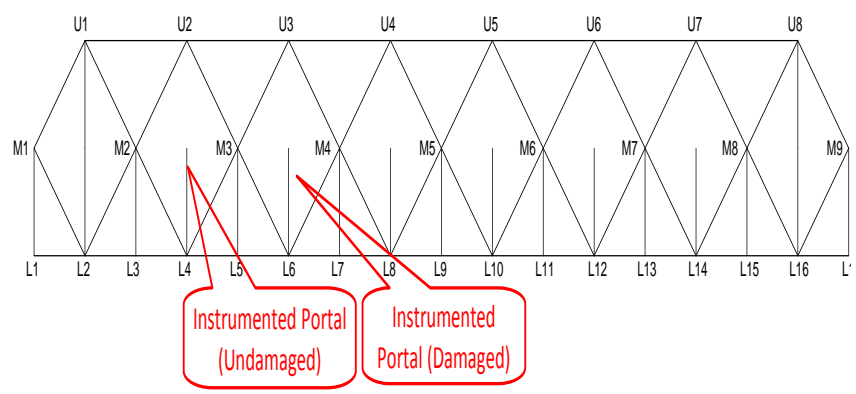

(a) Instrumented portals for strain measurement

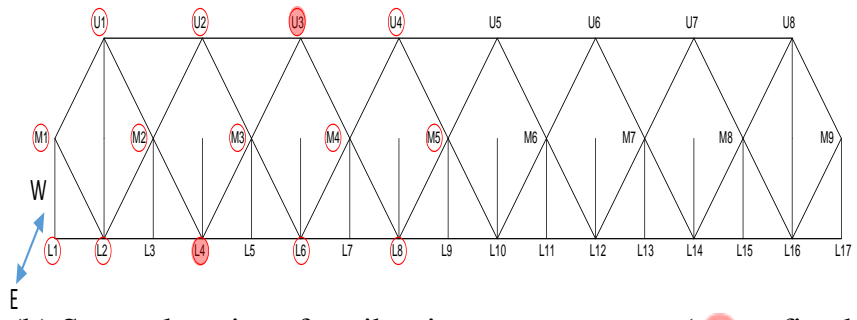

(b) Sensor locations for vibration measurement $(\odot$ = fixed Reference, $\bigcirc$ = roving accelerometer)

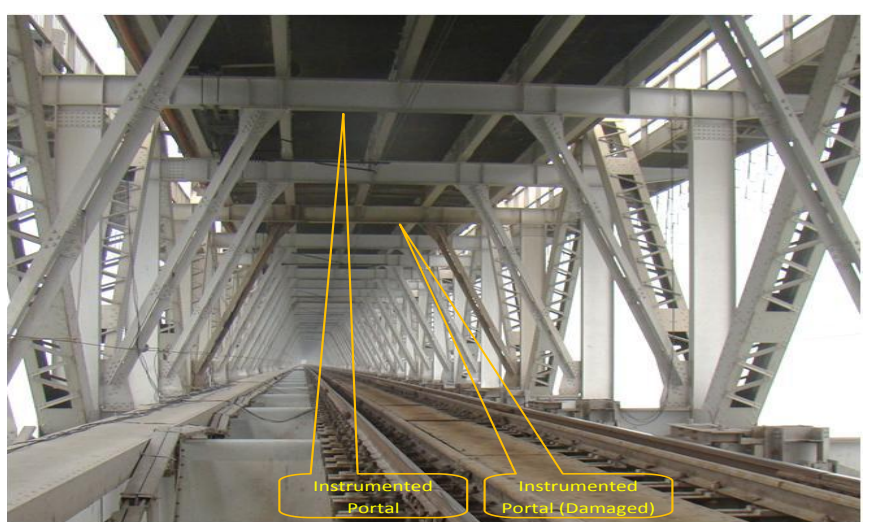




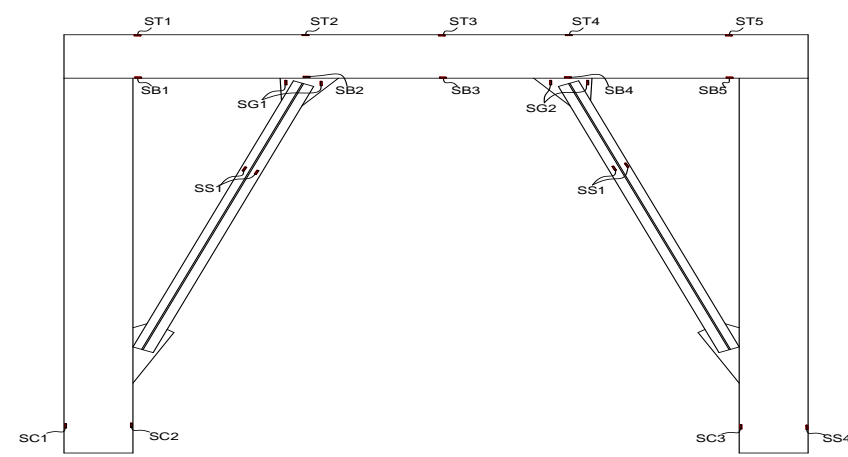

(c) Selected portals for instrumentation

(d)

Strain gage instrumentation on portal

Fig.3 Instrumentation Details adopted for field investigation The identified portals are shown in Fig. 3(a) and 6(c). The instrumentation scheme adopted on the portal is shown in Fig.3(d). The tower wagon provided by the railways for a limited block period is used for fixing of sensors and connection of cables to the sensors on the cross girders of the two portals. Instrumentation has also been carried out for measurement of vibration responses of the bridge span as shown in Fig.3(b). For this purpose, triaxial accelerometers have been fixed at all the node locations on the span of the bridge at three levels, viz., at rail level, road level and at top level of bracings. As the accelerometer sensors are limited, roving type of acceleration measurements are adopted by fixing two constant reference accelerometers for all test setups. Fixing of sensors on typical locations of the girder is shown in Fig.4.

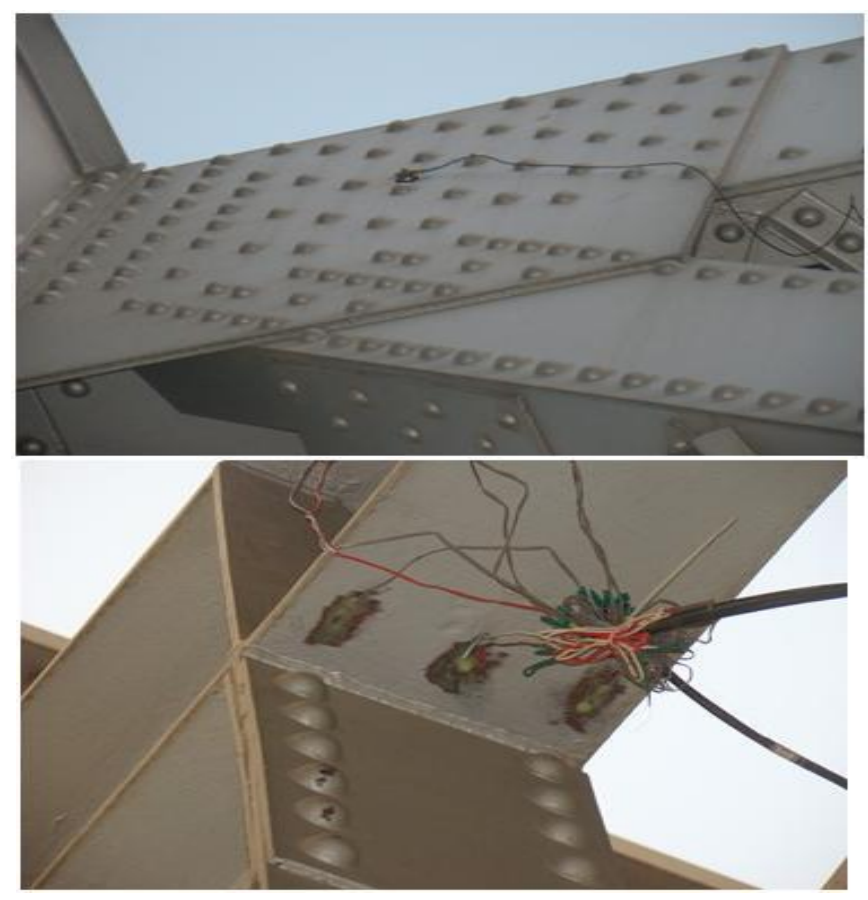

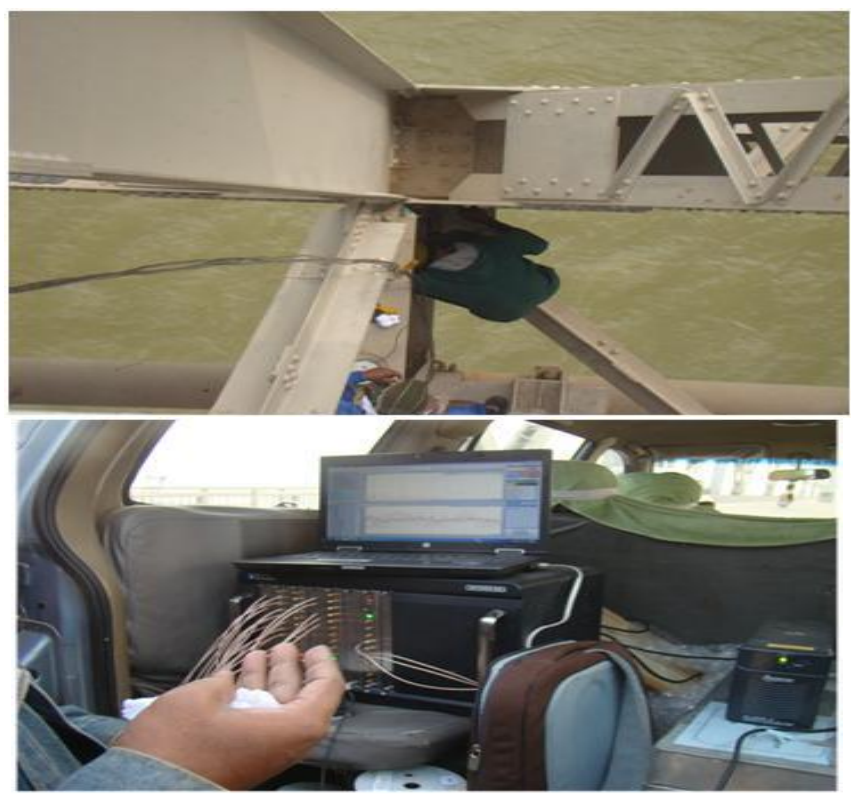

Fig.4 Fixing of sensors at typical locations and the measurement of responses using DAQ system

5. RESPONSE MEASUREMENTS

OF

\section{DAMAGED AND UNDAMAGED PORTAL} MEMBERS OF THE TYPICAL SPAN OF THE BRIDGE

Similar instrumentation scheme is adopted for both the undamaged and damaged portal frames and the responses are measured simultaneously during the passage of vehicles on the bridge. The bending strain at top and bottom flange of the girder are measured at support, above gusset and at mid span. The strain is found to be maximum at mid span bottom flange and is around 72.71microstrain and 142microstrain for undamaged and damaged frames respectively as can be observed from Fig.5. Torsional strain at both ends of cross girder are shown in Fig 6. Strain on gusset and star angle has also been measured and the responses are shown in Figs. 7 and 8 respectively.

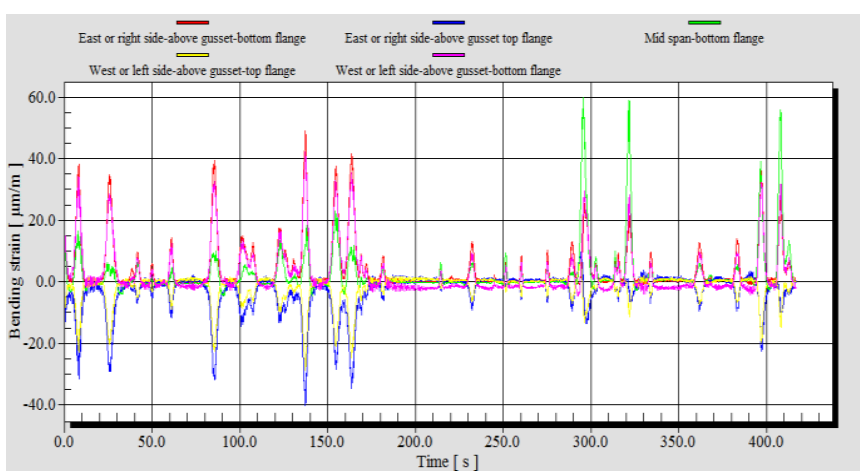

(a) Undamaged 


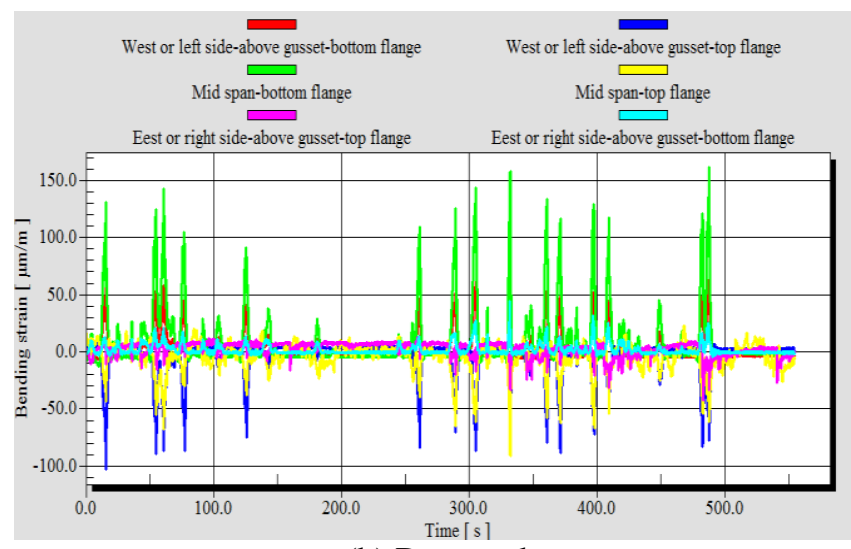

(b) Damaged

Fig. 5 Bending strain of cross girder

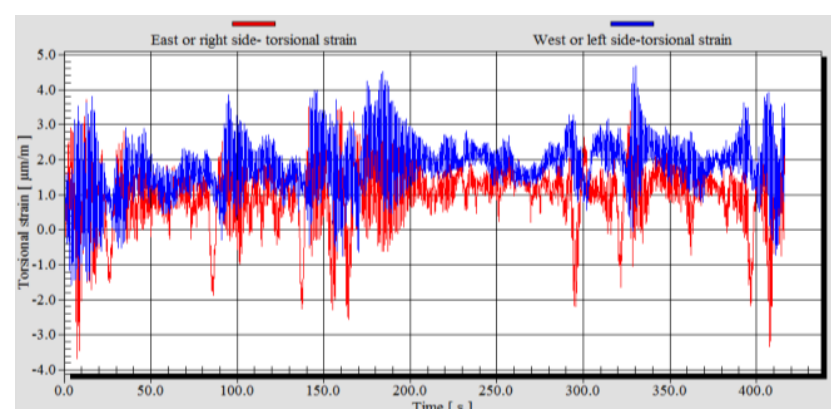

(a) Undamaged

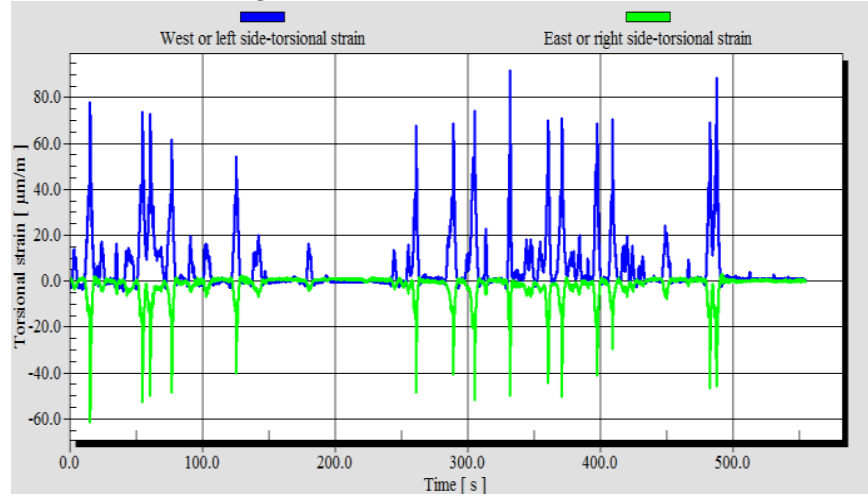

(b) Damaged

Fig. 6 Torsional strain at both fixed ends of cross girder

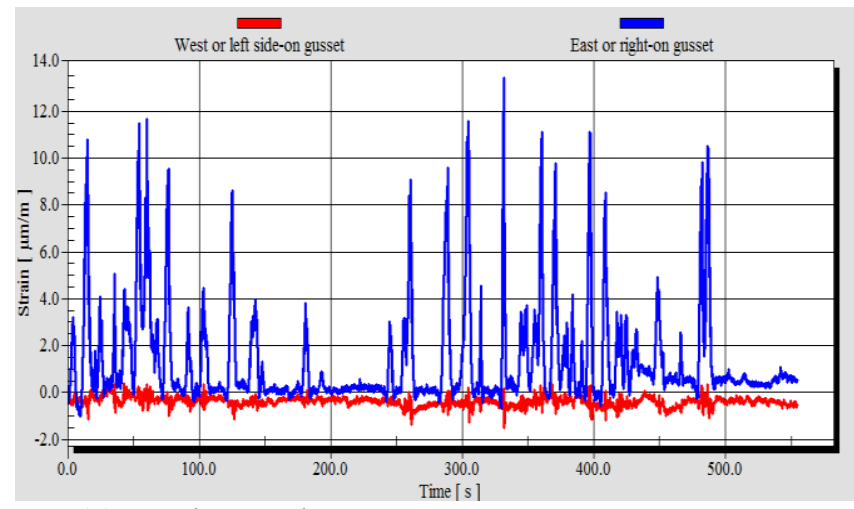

(a) Undamaged

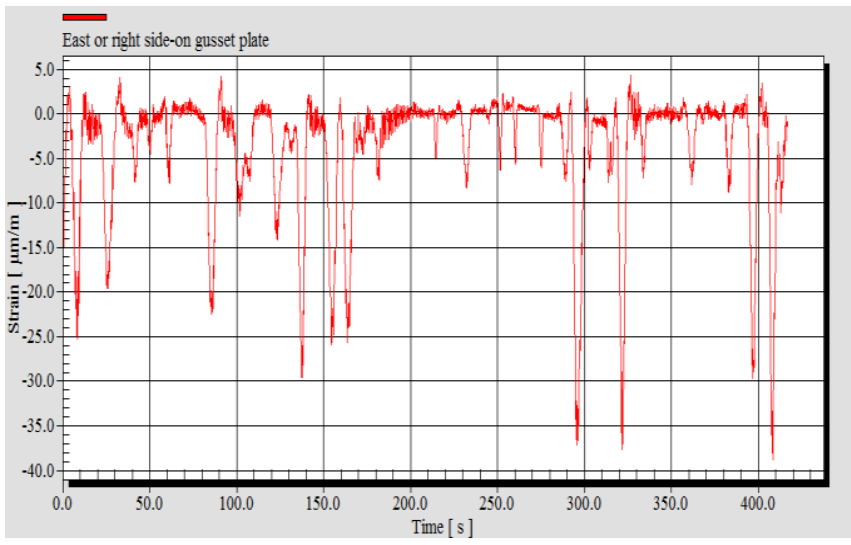

(b) Damaged

Fig 7: Strain on gusset plate

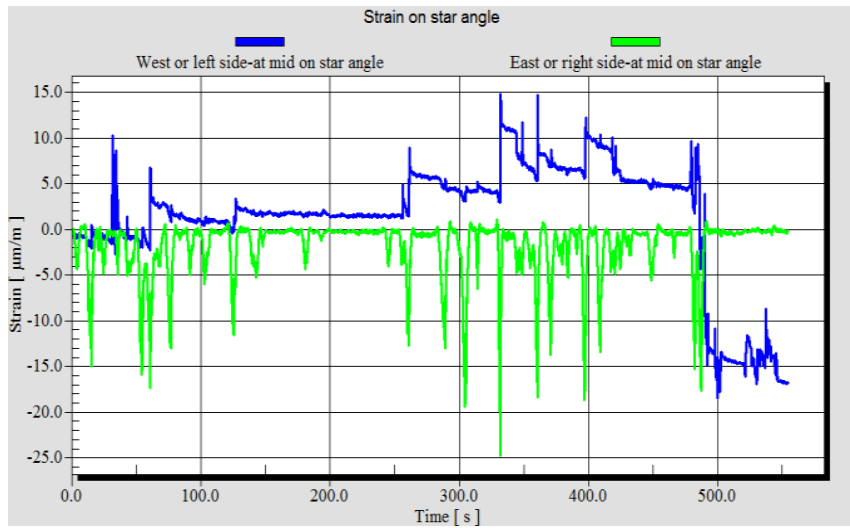

a) Undamaged

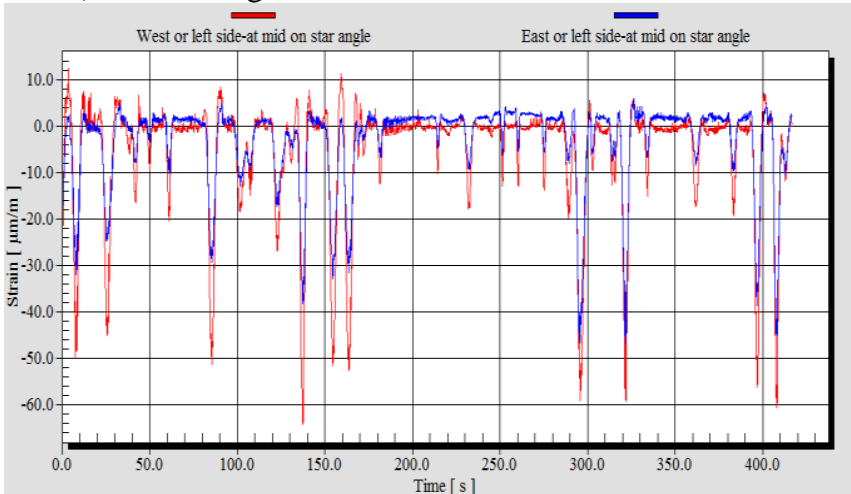

(b) Damaged

Fig. 8 Strain on star angle bracing

\section{OBSERVATIONS FROM THE MEASURED DATA}

From the responses of different sections of the cross girder, it is found that due to damage to the gusset, strain is not so high. Further, one of the gussets in star angles did not show any result due to no load transfer mechanism. It is important to mention here that the strain responses are obtained under the restricted traffic load on road, hence the magnitude is not very high. But the distribution of bending strains clearly reveals that there is considerable amount of torsion being produced due to the eccentric loading on the cross girder at intermediate expansion joints. In the case of 
undamaged cross girder, torsional strain produced at ends of cross girder (shown in Fig. 6) is almost nil and the bending strain developed at different sections of the cross girder and the star angles are considerably lesser than that observed in damaged cross girder. It clearly emphasises that the undesirable force flow mechanism in the cross girder at intermediate expansion joint, which needs to be mitigated.

\section{VIBRATION RESPONSES OF THE BRIDGE SPAN}

Vibration measurements are acquired on the bridge span by the accelerometers fixed at the node locations at three levels. Acceleration measurements have been taken for all the three directions at all the nodes to observe the vibration behaviour and vibration amplitude in longitudinal, lateral and in vertical direction of the bridge span. Typical vibration responses in terms of acceleration are shown in Fig. 9.

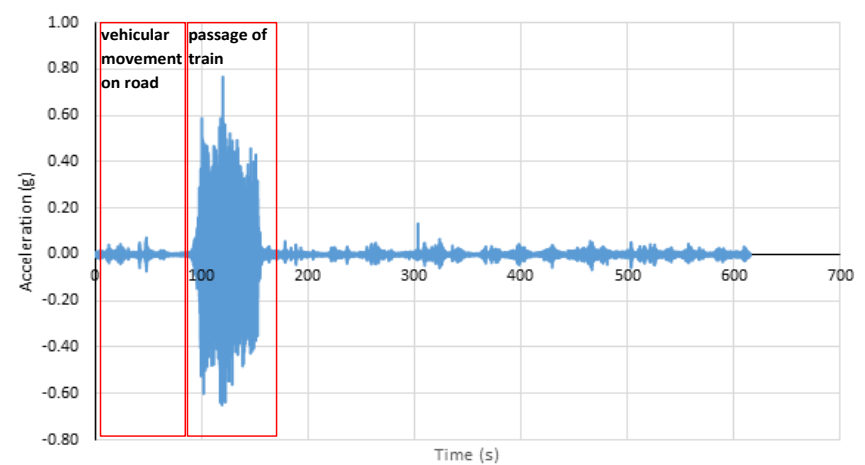

(a) vertical direction

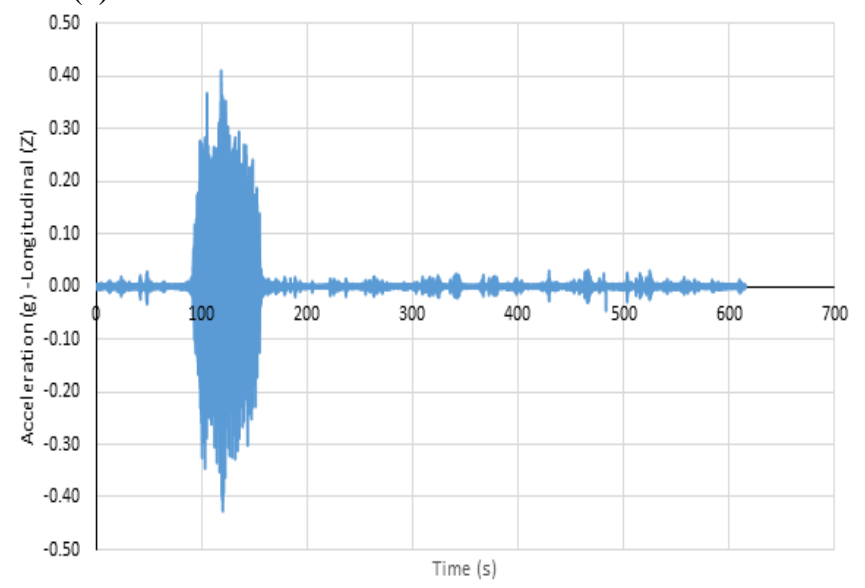

(b) longitudinal direction

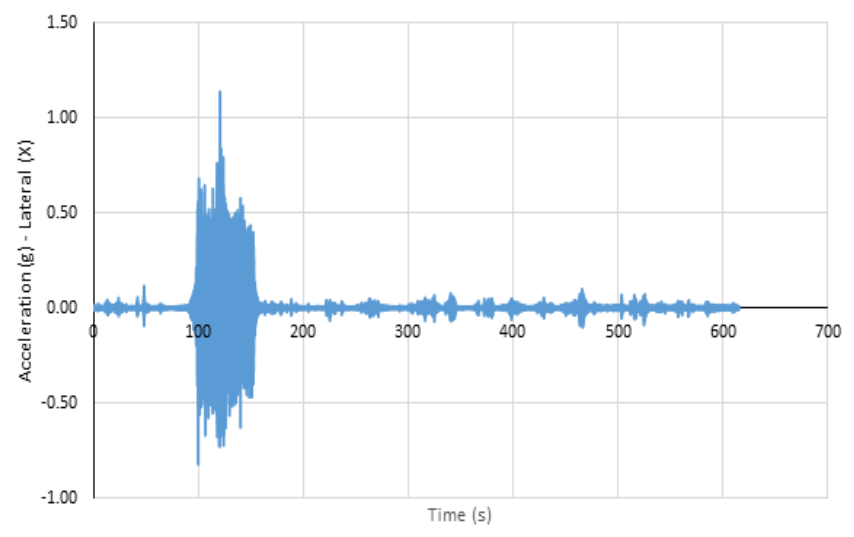

(c) lateral direction

Fig. 9 Typical vibration responses of the bridge span

It is observed that the bridge experiences tolerable vibration levels in the case of vehicular movement on the roadway at top. However, large vibrations are observed during the passage of train over the railway track of the bridge. Vibration levels of $0.1 \mathrm{~m} / \mathrm{s}^{2}$ and $0.8 \mathrm{~m} / \mathrm{s}^{2}$ are observed in the case of vehicular traffic and train movement respectively. The higher vibration levels may be mainly due to the impact of vehicles when moving over the intermediate joints which are damaged and due to undulated and damaged road surface. Based on frequency analysis of the measured vibration responses based on auto power spectra (Fig.10), it is observed that the first fundamental frequency of the bridge is around $2.686 \mathrm{~Hz}$ and very closely spaced modes are observed.

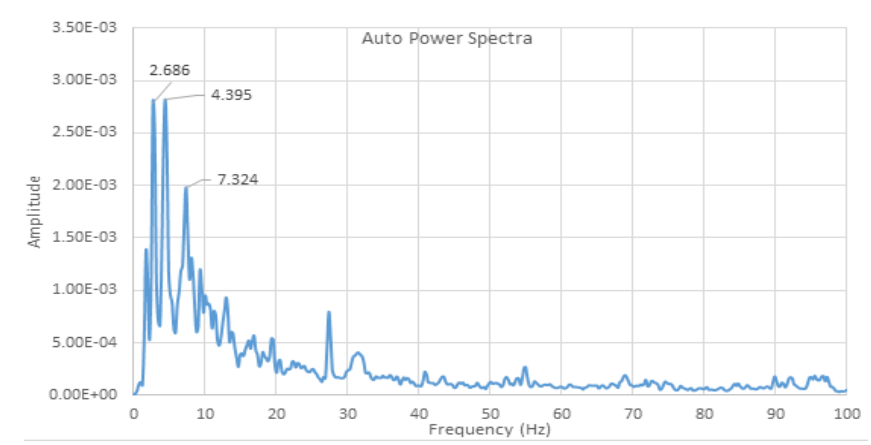

Fig. 10 Frequency spectra obtained from the vibration responses

\section{NUMEICAL MODELING TO ASSESS THE CAUSE OF DISTRESS IN THE PORTAL}

It is observed from the visual inspection and from the experimental measurements, that the load is being applied eccentrically at the tip of the flange of the cross girder at intermediate expansion joints causing additional stresses, moments and torsion in the member. To investigate and to further assess the cause for the additional stresses, 3D numerical modeling of the portal is carried out and the same loading which is obtained from the undamaged model of the portal that matches with the experimentally measured responses are applied eccentrically at the tip of the flange of the cross girder. Fig. 11 show the stress distributions (X direction, Y direction and von Mises) due to the eccentric 
loads applied in the portal frame representing the one at intermediate expansion joints. It can be seen from the plots that the gusset plate is being stressed more due to eccentric loading. It is found from the numerical study also, that the eccentric loads on the cross girder causes additional stresses due to torsion which are not considered in the design for the same. The bending of the gusset further causes additional stress in the flange and web of the cross girder causing the stresses to cross the limit which is the main reason for the cracking in the gusset which propagates further into the web of the cross girder. Hence, it has been concluded that the cause for damage in gusset plate is eccentric loading on the cross girders at intermediate expansion joints.

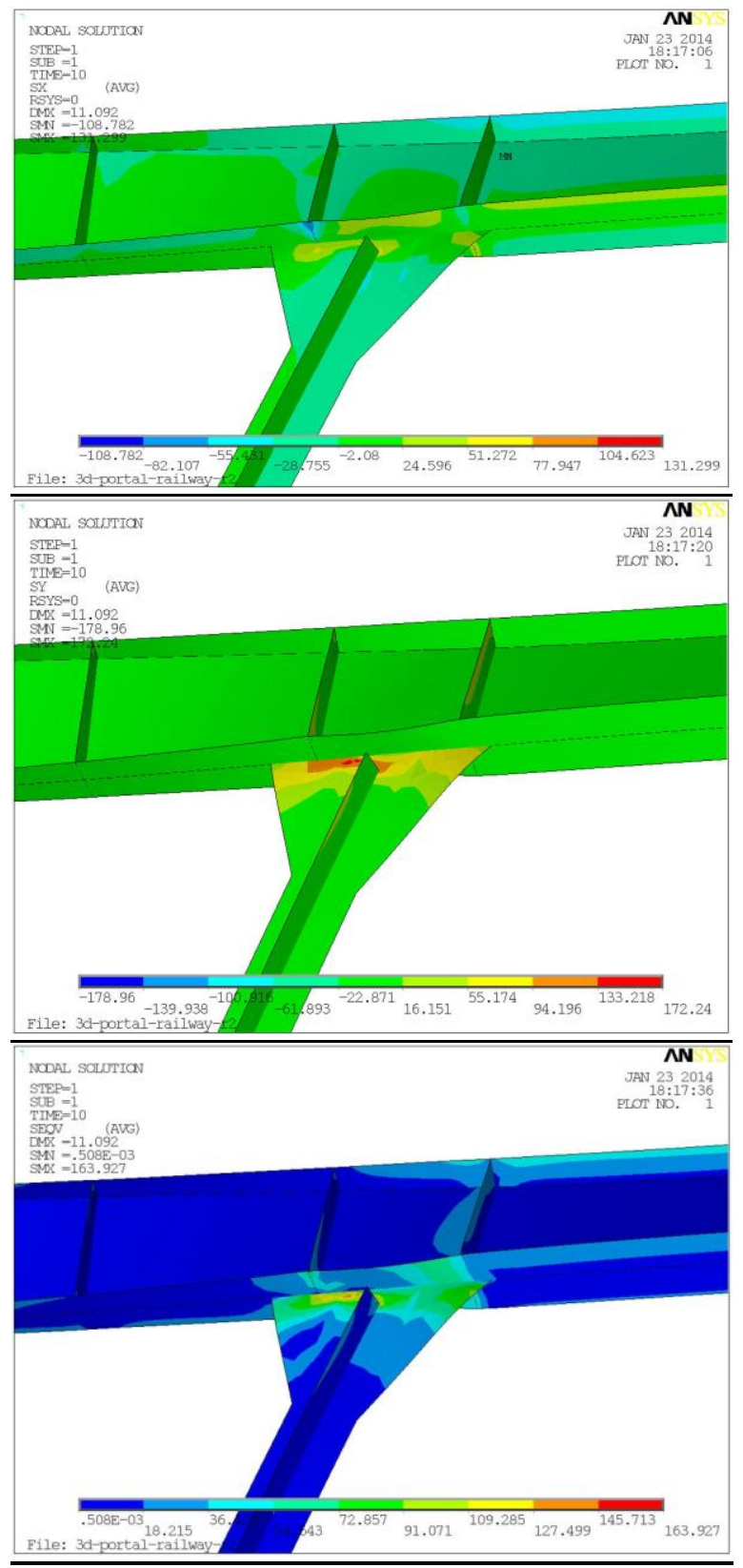

Fig. 10 Stress distribution in the eccentrically loaded portal frame representing damaged

(X direction stress, Y direction stress and von-Mises direction stress)

\section{RECOMMENDATIONS FOR} RETROFITTING SCHEME

It is observed from the measured strains from the instrumented portals of undamaged and damaged as well as from the numerical modeling of the same portal with concentric and eccentric loading representing the loading experienced at intermediate expansion joints that when the designed IRC loads are applied on the cross-girder, the portal members at intermediate expansion joint experiences the stresses which are above the permissible level giving rise to cracking of the members. This is found to be due to the torsional moments caused by the eccentric loading on the flange of the cross girder which is also correlated with the analytical calculations. Hence, in order to minimize the torsional effect on the cross girder due to eccentric loading, a suitable modification of the cross girder has been formulated as a retrofitting scheme to cater for the additional stresses due to torsion. In order to reduce the stress in the gusset plate, the cross girders have to be designed to take up the eccentric load. Hence box shaped cross girders are being suggested. The present I-section cross girder at the intermediate expansion joints can be modified to a box section with more width than the existing flange of the Isection so as to have more bearing area for the stringers positioned on the cross girder.

\section{CONCLUSIONS}

Full scale field investigations and response measurements were carried out on an open web girder type road cum railway bridge in order to assess the cause for damage to the bridge and to evolve the suitable retrofitting schemes. Based on the measured responses and from the numerical modelling of the damaged and undamaged portals, it was observed that the distress in the gusset and cross girder is mainly due to the load on the flange of the cross girder of the portal which is applied eccentrically. The strain measurements on the cross girder, gusset, bracing and vertical member of the two typical portals shows that the damaged portal experiences more bending strains than the undamaged portal. The excessive stresses are observed to be mainly because of the failure of seating at the intermediate joints and application of eccentric loads. The undulated and damaged road surface is also the cause for the vibration of the bridge during movement of road traffic. To mitigate the damage in the cross girder and the gussets, a suitable modification of the cross girder is suggested. A closed box section is suggested in place of existing I-section to cater for the torsional stresses being developed because of the eccentric loads on the cross girder at intermediate expansion joint. Thermal analysis of the modified structural system has been carried out and it is found that the stress state is within the permissible limit. 


\section{ACKNOWLEDGEMENTS}

This paper is being published with the kind permission of the Director, CSIR-Structural Engineering Research Centre, Chennai, India. This work is carried out as part of the project sponsored by East Central Railway (ECR) and the support provided by East Central Railway during the field investigations are gratefully acknowledged.

\section{REFERENCES}

[1]. Ruge, P. and Birk, C. (2007). "Longitudinal forces in continuously welded rails on bridge decks due to nonlinear track-bridge interaction", Computers and Structures, 85, 458-475.

[2]. Brownjohn, J.M.W, Moyo, P., Omenzetter, P., and Chakraborty S., "Lessons from monitoring the performance of highway bridges" -Structural control and health monitoring 2005, 12 , pp 227 to 244.

[3]. Otter, Duane E., LoPresti, Joseph, Foutch, Douglas A., and Tobias, Daniel H., "Longitudinal Forces in an Open-Deck Steel Deck Plate-Girder Bridge," Volume 98, Bulletin 760, American Railway Engineering Association, May 1997, PP. 101-105.

[4]. Otter, Duane E., Sweeney, Robert A.P., Dick, Stephen M., "Development of Design Guidelines for Longitudinal Forces in Bridges" Technology Digest 00-18, 2000, TTCI Pueblo, CO.

[5]. American Railway Engineering and Maintenance of Way Association Manual of Recommended Practice, Chapters 7, 8, 15 and 19, 2002, AREMA, Landover, MA.

[6]. Maragakis, E., Douglas, B., and Chen, Q. (2001). "Full-Scale Field Failure Tests of Railway Bridge", ASCE Journal of Bridge Engineering, 6(5), 356-362.

[7]. Karoumi, R., Wiberg, J. and Liljencrantz, A. (2005). "Monitoring traffic loads and dynamic effects using an instrumented railway bridge", Engineering Structures, 27(12), 1813-1819.

[8]. Caglayan, O., Ozakgul, K. and Tezer, O. (2012). "Assessment of existing steel railway bridges", Journal of Constructional Steel Research, 69(1), 5463.

[9]. Costa, B.J.A and Figueiras, J.A. (2012). "Evaluation of a strain monitoring system for existing steel railway bridges", Journal of Constructional Steel Research, 72, 179-191.

[10]. Esmaeili, M. and Fatollahzadeh, A. (2012), "Effect of Train Live Load on Railway Bridge Abutments", ASCE Journal of Bridge Engineering., (online) doi: 10.1061/(ASCE)BE.1943-5592.0000393

[11]. Rocha, J.M., Henriques, A.A. and Calçada, R. (2012). "Safety assessment of a short span railway bridge for high-speed traffic using simulation techniques", Engineering Structures, 40, 141-154.

[12]. V. Srinivas, K.Ramanjaneyulu, K.Saravana Kumar, S. Parivallal, K. Kesavan, K. Ravisankar, N. Lakshmanan, \& Nagesh R. Iyer, "Evaluation of Longitudinal Force on a Railway Bridge Based on
Strain Measurements", Experimental Techniques, 37(1), 2013, 55-67.

[13]. V. Srinivas, Saptarshi Sasmal, K. Ramanjaneyulu, K. Ravisankar, "Performance Evaluation of a Stone Masonry-Arch Railway Bridge under Increased Axle Loads", ASCE Journal of Performance of Constructed Facilities, 28(2), 2014, 363-375.

[14]. V. Srinivas, Saptarshi Sasmal, Nawal Kishor Banjara, K. Ramanjaneyulu, and Nagesh R. Iyer, "Health Assessment of a Plate Girder Railway Bridge under Increased Axle Loads", ASCE Journal of Bridge Engineering, Vol. 18, No. 10, October, 2013, pp. 969-979.

[15]. Indian Railway Standard (2005) Rules specifying the loads for design of super-structure and Sub-structure of bridges (Bridge Rules), RDSO, Lucknow, India.

[16]. IRC:6-2000, Standard Specifications and Code of Practice for Road Bridges, Section: II, Loads and Stresses. The Indian Road Congress, New Delhi, 2000 . 